\title{
CONSCIÊNCIA AMBIENTAL NAS LICITAÇÕES COMO CONDIÇÃO SINE QUA NON NO DESENVOLVIMENTO SUSTENTÁVEL
}

\section{ARTIGO ORIGINAL}

SÚAREZ, Jacyara da Silva Moraes Rondon ${ }^{1}$

SÚAREZ, Jacyara da Silva Moraes Rondon. Consciência ambiental nas licitações como condição sine qua non no desenvolvimento sustentável. Revista Científica Multidisciplinar Núcleo do Conhecimento. Ano 04, Ed. 03, Vol. 08, pp. 100-124. Março de 2019. ISSN: 2448-0959.

\section{RESUMO}

O Estado brasileiro é o maior contratante de bens, obras e serviços. O volume dos empreendimentos estatais impulsiona a economia e condiciona o surgimento, prosperidade e desaparecimento de conglomerados empresariais. Ao licitar, obrigação da qual não pode escapar, a Administração Pública não está liberada de atender os princípios fundamentais da República. Nem se isenta de cumprir o preceito do artigo 225 da Carta Federal, que Ihe impõe, assim como à coletividade, defender e preservar o meio ambiente. No momento em que as ameaças à subsistência de vida no planeta deixam o capítulo do catastrofismo para assumirem consistência e proximidade, o Estado já não pode se contentar com o menor preço. A temática da sustentabilidade e do consumo responsável é, na atualidade, algo que não pode ser desconsiderada, sequer pelo individuo, quiça por parte do Estado consumidor. A adoção de critérios sustentáveis, vai fortalecer o mercado da indústria ecológica no País. A Administração Pública consumista vai dar lugar a uma Administração pública consciente e diretiva.

\footnotetext{
${ }^{1}$ Pós-graduada em Direito Administrativo (Universidade Estácio de Sá - RJ), MBA em Gestão Pública (Universidade Gama Filho - RJ), Bacharela em Administração (UFMS).
} 
Palavras - chave: Administração, Meio Ambiente, Licitação, Sustentabilidade.

\section{INTRODUÇÃO}

O mundo não é mais o mesmo. A consciência das pessoas está mudando. Faz-se necessário o consumo mais seletivo, para que pessoas que não consumiam antes, $\mathrm{e}$ que necessitam disto para seu bem estar, o façam. É necessário que não se gaste mal os recursos naturais como a água, as fontes de energia renováveis e não renováveis, para que mais pessoas, que precisam deles, também as usufruam. Devemos fazer algo com o lixo de nossas cidades, para que ele não nos intoxique, seja com seus excessos, seja com seus resíduos.

O desenvolvimento de uma consciência ambiental pelos gestores públicos para a devida inserção de critérios de sustentabilidade nas licitações e contratações está além das alterações legislativas já vigentes, e ignoradas por alguns, encontra-se mais intrinsicamente ligada à necessidade de uma mudança cultural para valorização do meio ambiente.

As mudanças advindas com a Lei ํㅜ 12.349/2010, modificando o art. $3^{\circ}$ da Lei $n^{\circ}$ 8.666/93 trouxe novas formas para especificar os bens e serviços objetos de licitação. Cabe agora aos gestores públicos darem efetividade às licitações sustentáveis, dando o devido enfoque de sustentabilidade aos editais e termos de referência.

Assim, a relevância do tema encontra justificativa nos anseios sociais da atualidade brasileira, no que se refere ao desenvolvimento sustentável, preservação ambiental e valorização da vida e, dentro desse contexto, a atuação da Administração Pública na busca desses objetivos.

A sustentabilidade tem importância para o planeta pela sobrevivência de todos os seres que nele habitam. Ninguém melhor do que a própria Administração Pública para tomar as rédeas desta situação, dando exemplo e formando um mercado neste sentido, por meio de licitações sustentáveis. 
O Brasil é a nação dos paradoxos. No processo de consolidação do conceito de sustentabilidade, teve papel fundamental. O ambientalista Paulo Nogueira Neto participou da elaboração do Relatório Brundtland da Comissão Mundial sobre o Meio Ambiente e Desenvolvimento. Hospedou a Eco 92, durante a qual Mikhail Gorbatchev fez uma advertência a que pouco se atentou: a humanidade teria 30 anos para se converter e alterar seus hábitos de consumo. Depois disso a Terra poderia continuar a existir, mas prescindiria da vida para seguir o seu destino.

Já em Joanesburgo, em 2002, a reunião Rio +10 evidenciou um retrocesso até na principiologia proclamada na Eco 92. Em seguida, recrudesceu o embate entre o agronegócio e a preservação. $\mathrm{O}$ ambientalismo recuou e prevaleceu o interesse imediato de uma exploração ecologicamente nefasta. Da qual o exemplo mais emblemático é a mutilação do Código Florestal, com a flexilização de exigências postas em 1965, muito antes do agravamento da situação da combalida cobertura vegetal, hoje praticamente em chamas. A Rio +20 chegou ao final com resultados tímidos e promessas adiadas.

Paradoxalmente, surgem diversas obras a respeito da sustentabilidade, tema hoje em evidência, e vemos esforços das grandes empresas para redução de seus impactos ambientais.

Este artigo busca, portando uma breve divagação sobre licitações sustentáveis, entender o relacionamento do poder de compra da Administração Pública por meio da licitação, e seu impacto sobre o meio ambiente. E ainda, dentro desse contexto, demonstrar como a administração pública vem promovendo o desenvolvimento sustentável no Brasil por meio das licitações e se os resultados alcançados são compatíveis com as perspectivas traçadas internacionalmente.

Nesse contexto o artigo está dividido em quatro seções, incluindo-se a introdução e considerações finais. A Seção 1 traz a introdução. A Seção 2 trata dos conceitos de licitações sustentáveis e sobre as leis de Mudanças Climáticas e Resíduos Sólidos, buscando o entendimento legal das licitações sustentáveis. A seção 3 trata do panorama geral sobre licitações sustentáveis buscando entender o a nova maneira de 
agir da Administração Pública, a Seção 4 traz as considerações finais da presente pesquisa e a Seção 5 as referências bibliográficas.

A metodologia utilizada para elaboração consistiu em pesquisa bibliográfica a algumas das principais bibliotecas do Rio de Janeiro, mas não se restringiu apenas ao acervo bibliográfico, ademais, aos ensinamentos do Professor Dr. Alexandre Santos do Aragão notável doutrinador do referido assunto. E ainda, houve consultas à rede mundial de computadores.

Espera-se que esse artigo corrobore com as discussões já existentes sobre o tema, e sirva como fonte de pesquisa em uma área de conhecimento repleta de controvérsias, porém de inesgotável relevância contemporânea, tendo em vista sua vital importância literária. Ressalta-se o famoso proverbio indígena também utilizado pelo Greenpeace "Só quando a última árvore for derrubada, o último peixe for morto e o último rio for poluído é que o homem perceberá que não se pode comer dinheiro".

\section{CONCEITO DE LICITAÇÃO}

Licitação, em linhas bem simples, é o " processo administrativo que, tendo em vista futura contratação, destina-se a selecionar a proposta mais vantajosa para Administração".

Meirelles (2011, p. 257) esclarece que, como procedimento, a licitação desenvolve-se por uma sucessão ordenada de atos vinculantes para a Administração e para os licitantes, a propiciar igual oportunidade a todos os interessados e maior eficiência e moralidade nos negócios administrativos.

Di Pietro (2008, p. 299), define licitação como procedimento administrativo pelo qual um ente público, no exercício de sua função administrativa, abre a todos os interessados, desde que estes se submetam às condições estabelecidas em edital, a possibilidade de apresentarem propostas, das quais selecionará e aceitará a mais vantajosa para a celebração do contrato. 
Araújo (2010, p. 495) tomou como objeto de análise o conceito de licitação colocado pelo legislador no art $3^{\circ}$ da Lei 8.666/93. O dispositivo é dividido em duas partes: a primeira explicaria a finalidade da licitação, o resultado que se almeja com a sua realização; a última parta enumeraria os princípios que deverá nortear o procedimento, princípio da legalidade, isonomia ou igualdade de todos perante a lei (princípios gerais constitucionais), a impessoalidade, a moralidade, a publicidade dos atos administrativos, a probidade, a vinculação ao instrumento convocatório, o julgamento objetivo, sem olvidar os princípios correlatos.

O citado jurista conclui, com estas palavras: "a conceituação legal da licitação a inclina ao duplo objetivo de proporcionar à Administração a possibilidade de realizar o negócio mais vantajoso e propiciar aos administrados a oportunidade de, em igualdade de condições, se candidatar ao contrato com a Administração", fazendo referência a Antônio Roque Citadini e Eros Roberto.

\subsection{CONCEITO DE SUSTENTABILIDADE}

Segundo Trigueiro (2005, p. 82) "O conceito foi introduzido no início da década de 1980 por Lester Brown, fundador do Wordwatch Institute, que definiu comunidade sustentável como a que é capaz de satisfazer às próprias necessidades sem reduzir as oportunidades das gerações futuras."

Canepa (2007, p. 71) esclarece que, junto com a discussão da sustentabilidade, encontra-se o conceito de qualidade de vida; o termo teria relação com viver e sobreviver: " a vida em plenitude, usufruindo tudo quanto for necessário para, além de mera sobrevivência física, obter a realização de suas finalidades".

Sanchs (2000, p. 54) aborda sustentabilidade como a busca pela harmonização de objetivos sociais, ambientais e econômicos, que foi inicialmente chamada de ecodesenvolvimento e posteriormente, desenvolvimento sustentável, elencando como os três objetivos da sustentabilidade: 
1. Preservação potencial da natureza para a produção de recursos renováveis;

2. Limitação do uso de recursos não renováveis; e

3. Respeito e realce para a capacidade de autodeparação dos sistemas naturais.

\subsection{LICITAÇÕES SUSTENTÁVEIS}

Partindo das definições acima, como ponto de partida para um maior aprofundamento, o que então, seriam as chamadas licitações sustentáveis? Tema esse, foco do trabalho.

Seria contratar (comprar, locar, tomar serviços...), adequando a contratação ao que se chama consumo sustentável, meta da Agenda Ambiental na Administração Pública, levando em conta que o governo é grande comprador e grande consumidor de recursos naturais, os quais não são perpétuos. Como o governo compra muito poderia estimular uma produção mais sustentável, em maior escala, além de dar o exemplo.

Em suma licitações sustentáveis seriam aquelas que levariam em conta a sustentabilidade ambiental dos produtos e processos a elas relativos. Como observou o Partido Verde do Paraná, a introdução do pregão eletrônico já possibilitou uma sensível economia dos recursos materiais utilizados para levar a cabo o processo licitatório. Para este último o grande problema consistiria que, embora a Lei 8666/93 considere o impacto ambiental no projeto básico de obras e serviços públicos, não haveria norma legal específica relativamente às compras. Ou seja, seria possível a exigência, numa licitação, de "produtos que contemplem o conceito de sustentabilidade ambiental", não havendo, uma regulamentação, que a torne obrigatória, o que muito contribuiria para as licitações sustentáveis.

Para governos e estudiosos europeus, a licitação sustentável seria também uma solução para integrar considerações ambientais e sociais em todos os estágios do processo da compra e contratação dos agentes públicos com o objetivo de reduzir impactos à saúde humana, ao meio ambiente e aos direitos humanos. A licitação 
sustentável permitiria o atendimento das necessidades especificas dos consumidores finais por meio da compra do produto que oferece o maior número de benefícios para o ambiente e a sociedade.

A licitação sustentável, também, denominada "ecoaquisição", "compra verde", "licitação positiva" ou "compra ambientalmente amigável", tem como objetivo precípuo utilizar o poder de compra estatal visando a propiciar uma postura sustentável das empresas, que terão de se adequar às exigências caso queiram vender para o setor público.

A licitação sustentável ampara-se em uma nova interpretação da premissa de que o comprador público deve utilizar a licitação como instrumento para realizar a compra do melhor produto/serviço pelo menor preço.

Essa nova visão, de cunho regulatório, que se pretende ampliar para toda Administração Pública, tem como objetivo conferir maior eficácia social ao comando da Constituição Federal de 1988, que traz entre seus princípios a obrigação do poder público de garantir um meio ambiente equilibrado (art. 225), além de incluir, a defesa do meio ambiente como um dos princípios gerais da atividade econômica (art. 170, $\mathrm{CF})$.

\subsection{OBRAS E SERVIÇOS SUSTENTÁVEIS}

O conceito de Desenvolvimento Sustentável foi utilizado pela primeira vez no Relatório Brundtland (1987), Comissão Mundial sobre o Meio Ambiente e Desenvolvimento (ONU):

"aquele que atende às necessidades do presente sem comprometer a possibilidade de as gerações futuras atenderem suas próprias necessidades".

Com relação a obras e serviços sustentáveis, a polêmica não tem sido tão grande, uma vez que a própria Constituição Federal, por ocasião de sua promulgação, já traçava caminhos nesta direção. 
O inciso VI do art. 170 previa, à época, como um dos princípios da ordem econômica nacional a defesa do meio ambiente, e o inciso IV do art. 225 já exigia, para toda instalação de obra ou atividade potencialmente causadora de significativa degradação do meio ambiente, estudo prévio de impacto ambiental. Aliás, tais previsões constitucionais passaram a se coadunar com a Política Nacional do Meio Ambiente prevista no país pela Lei oㅡ 6.938, de 31.08.1981.

O art. $4^{\circ}$ da Lei $n^{\circ} 6.938 / 81$ já determinava que a Política Nacional do meio Ambiente visaria, dentre outros objetivos, à compatibilização do desenvolvimento econômicosocial com a preservação da qualidade do meio ambiente e do equilíbrio ecológico; ao desenvolvimento de pesquisas e tecnologias nacionais orientadas para o uso racional de recursos ambientais; à divulgação de dados e informações ambientais voltados à formação de uma consciência pública sobre a necessidade de preservação da qualidade ambiental e do equilíbrio ecológico; bem como a preservação e restauração dos recursos ambientais para que estes sejam utilizados de forma racional e ocorra a sua disponibilidade permanente, a concorrer para manutenção do equilíbrio ecológico propicio a vida.

O parágrafo único do art $5^{\circ}$ da Lei $n^{\circ} 6.938 / 81$ ainda imporia que as atividades empresariais públicas e privadas sejam exercidas em conformidade com as diretrizes da Política Nacional do Meio Ambiente, determinando o art. 10 do mesmo diploma legal que a construção, instalação, ampliação e funcionamento de estabelecimentos e atividades que utilizem recursos ambientais, efetiva ou potencialmente poluidores, ou que sejam capazes de causar degradação ambiental, dependerão de prévio licenciamento do órgão estadual ambiental, integrante do Sistema Nacional do Meio Ambiente e do Instituto Brasileiro do Meio Ambiente e Recursos Naturais Renováveis, em caráter supletivo.

Foi com base no inciso VI do art. 170 e no inciso IV do art. 225 da Constituição Federal, bem como a Lei o 6.938/81, que o art. 12 da lei o 8.666/93 dispunha, desde sua edição, em 21.6.1993, que nos projetos básico e executivo de obras e serviços sejam considerados, principalmente, determinados requisitos, dentre os quais a segurança; a possibilidade de emprego de mão de obra, materiais, tecnologia e matérias-primas 
existentes no local para execução, conservação e operação; adoção de normas técnicas, de saúde e segurança do trabalho adequadas; e o impacto ambiental.

Posteriormente a Lei no 11.079, de 30.12.2004, que instituiu normas para licitações e contratações de parcerias público-privadas, incluiria, como uma das diretrizes deste tipo de contratação, consiste em concessão de serviços ou de obras públicas ou a prestação de serviços ou de obras públicas ou a prestação de serviços de que a Administração Pública seja a usuária direta ou indireta, havendo, em ambos os casos, contraprestação pecuniária do parceiro público ao parceiro privado, a "sustentabilidade financeira e vantagens socioeconômicas dos projetos de parceria"

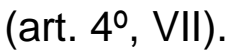

No que tange à contratação de obras e serviços de forma sustentável, não haviam maiores controvérsias, uma vez que existem normas constitucionais e legais expressas a respeito.

\subsection{COMPRAS SUSTENTÁVEIS}

Se as obras e serviços sustentáveis já eram admitidos pelo legislador, num sistema que continha demandas judiciais injustificáveis, as compras públicas possuem um panorama diferenciado.

Examinando no que consiste o poder de compra do governo, Stroppa (2013) define a prerrogativa que tem o consumidor de definir suas exigências e necessidades, tornando-se um indutor de qualidade, produtividade e inovação tecnológica e, sendo o Estado um grande comprador, ele poderia usar deste "poder" para fomentar o desenvolvimento socioambiental.

Uma compra pública sustentável buscaria integrar critérios ambientais, sociais e econômicos a todos os estágios deste processo de licitação. O comprador público considerará a necessidade real de adquirir; as circunstâncias em que o produto visado será gerado, levando ainda em relação os materiais e as condições de trabalho de quem o gerou. 
Muitas pessoas criticam as compras sustentáveis sob o argumento de que estes produtos/bens teriam preços mais altos. O Governo do Estado de São Paulo, que já fez licitações deste tipo, alerta que " produtos diferentes possuem preços diferentes. As especificações técnicas são diferenciadas, pois têm atributos específicos". Caso os atributos desta especificação tiverem características ambientalmente ou socialmente importantes, pode ocorrer que isto provoque um acréscimo de preço na compra, mas haverá uma vantagem econômica a longo prazo para a Administração Pública, no decorrer de sua vida útil. A título de exemplo, as lâmpadas fluorescentes geralmente são mais caras que as lâmpadas incandescentes (comuns), gastando, contudo, menos energia elétrica.

Ademais seria necessária uma educação correspondente aos servidores e terceirizados que trabalham nas repartições públicas, pois somente uma mudança de cultura, de ver as coisas, permitiria tal implementação.

Além disto o princípio da economicidade impõe que os recursos financeiros sejam geridos de modo adequado para que se obtenham os maiores benefícios pelos menores custos.

Stroppa (2013) entende que isto poderá ser atingido com contratos com preços iguais ou inferiores à média dos preços de mercado ou com preço justo pela qualidade do seu objeto, não havendo, necessariamente, uma incompatibilidade com a licitação sustentável.

De outro lado não se deve olvidar que a Administração Pública defende 2 (dois) interesses: o primário (social) e o secundário (como qualquer pessoa física ou jurídica).

Mello (2011, p. 22) define que os interesses da coletividade como um todo e, os interesses secundários, como aqueles em que o Estado (pelo fato de ser sujeito de direitos poderia ter como qualquer outra pessoa, isto é independentemente de sua qualidade de servidor de interesses de terceiros. O dever do Poder Público de defender e preservar o meio ambiente ecologicamente equilibrado para as presentes 
e futuras gerações inserir-se-ia em interesse primário do Estado, pois este não interessaria somente a ele, pessoa jurídica, mas a toda coletividade.

Stroppa (2013) defende, ainda, a tese de que, num procedimento licitatório, o que se pretende é a melhor proposta no mercado e não na licitação.

(...) logo, se existem falhas de mercado, está justificada a intervenção do Estado na economia. $\mathrm{O}$ art. 173 da Constituição Federal permite que o Estado, em situações especiais, intervenha no domínio econômico quando necessária aos imperativos da segurança nacional ou a relevante interesse coletivo.

Para a citada autora, "possibilitar a promoção de iniciativas de licitação sustentável insere-se na noção de relevante interesse coletivo, a justificar o uso do instituto da licitação como instrumento de intervenção no mercado", dando um olhar " mais sustentável e menos financeiro da licitação".

\subsection{COMO CHEGAR A UMA LICITAÇÃO SUSTENTÁVEL}

O governo paulista deu passos significativos neste sentido. Nos certames paulistas, havendo necessidade de inserção de critérios socioambientais num determinado produto, eles fariam parte da especificação técnica. Isto ocorreria na fase interna de preparação da licitação. Somente após está caracterização seria elaborado o preço de referência do produto.

No caso dos pregões, modalidade de licitação para bens e serviços comuns, o legislador imporia uma licitação do tipo menor preço. Desta forma, conforme determina a Lei e o edital, o julgamento elegeria a melhor oferta proposta relativamente ao item licitado, o qual, por sua vez, estaria vinculado à especificação técnica previamente definida no edital.

Conforme dados da Bolsa Eletrônica de Compras do Estado de São Paulo: 
(...) "um item $A$ não compete com o item $B$, ou seja, papel sulfite não compete com papel reciclado para obtenção de menor preço entre os dois itens, pois cada um deles é um item diferente; detém códigos diferentes, preços referenciais diferentes, características diferentes, podendo ter quantidades diferentes e integrar uma mesma licitação ou não".

A Bolsa Eletrônica de Compras de SP informou que, em pregão feito apenas para produtos sustentáveis, que a resma de 500 folhas de papel reciclado de papelaria , gramatura 75G/M2 $(+/ 3,0)$, espessura $0,098 \mathrm{~mm}(+/-0,007)$, aspereza Bendtsen $250 \mathrm{ml} / \mathrm{min}$ (+/100), no formato A4, alcalino multiuso, compatível com copiadora e impressora acima de 100 cópias/min; resistência cera Dennison 12-16, norma NBRNM225/01; na cor palha, embalado em resmas, em papel revestido com filme polipropileno, original do fabricante, foi comprada pelo preço de $R \$ 8,50$, representando economia ao Estado, pois a resma de 500 folhas de papel sulfite comum já fora adquirida por $\mathrm{R} \$ 9,61$, no primeiro semestre de 2009 .

Alguém poderia indagar se incluir critérios socioambientais como forma de selecionar produtos e fornecedores com capacidade para habilitar às licitações sustentáveis seria uma forma de direcionamento, pelo fato de que há produtos no mercado que atendem a mesma finalidade?

A Dra. Silvia Helena Nogueira Nascimento, Procuradora-Chefe da Secretaria do Meio Ambiente do Estado de São Paulo, elaborou o Parecer CJ/SMA no 683/2006, no qual aborda a inserção de atributos socioambientais nas especificações técnicas. Para ela, a inserção revelar-se-ia possível graças ao art. 40, I, Lei ㄲo8.666/93, que manda a Administração descrever o objeto a ser contratado, de forma clara e objetiva, com todas as características necessárias ao atendimento do interesse público, incluindose neste último o respeito ao meio ambiente ecologicamente equilibrado.

O referido parecer não considera o inciso $1^{\circ}$, do art. $3^{\circ}$ do diploma legal licitatório como obstáculo para que a Administração Pública realize contratações ambientalmente sustentáveis, " ainda que eventualmente restritivas, se pertinentes, relevantes e 
motivadas, a própria lei admite que se façam distinções para a contratação objetiva pela Administração Pública, sempre em prol do interesse público" (inciso 40).

O mesmo parecer ainda ressalta que a própria Lei $n^{\circ} 11.196 / 05$ inseriu o inciso $2^{0}$ no

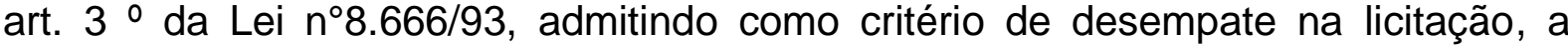
preferência para bens e serviços produzidos ou prestados por empresas que invistam em pesquisa e no desenvolvimento de tecnologia no país, sendo que "o desenvolvimento de pesquisas e tecnologia no Brasil voltadas à preservação do meio ambiente apresenta-se como de maior relevância para o país", a permitir o enquadramento das contratações sustentáveis no referido dispositivo ( inciso 41), levando-se em consideração a atuação do Brasil na Conferência das Nações Unidas sobre Meio Ambiente e Desenvolvimento, conhecida como ECO 92, realizada entre 3 e 14 de junho de 1992 no Rio de Janeiro, que adotou, na Agenda 21, o desenvolvimento sustentável como meta a ser alcançada pelos países, com estabelecimento de programas voltados ao exame dos padrões insustentáveis de produção e consumo, e de políticas estratégicas nacionais de estímulo a mudanças no padrão de consumo insustentável.

\subsection{A POLÍTICA NACIONAL DE RESÍDUOS SÓLIDOS}

A Lei $n^{0}$ 12.305, de 2.8.2010, que instituiu a Política Nacional de Resíduos Sólidos, destacou, em seu art. $7^{\circ}, \mathrm{XI}$, como um dos objetivos daquele diploma legal a prioridade nas aquisições e contratações governamentais de produtos reciclado e recicláveis, bem como de bens, serviços e obras que considerem critérios compatíveis com padrões de consumo social e ambientalmente sustentáveis, a permitir, expressamente, a implantação de licitações sustentáveis como um dos interesses primários a serem defendidos por parte de todos os entes federativos.

A partir da entrada em vigor da lei de resíduos sólidos, a Administração Pública não está obrigada a contratar com quem estiver descumprindo a lei.

Assim dispõe o art. 25 da citada lei: 
Art.25. O poder público, o setor empresarial e a coletividade são responsáveis pela efetividade das ações voltadas para assegurar a observância da Política Nacional de Resíduos Sólidos e das diretrizes e demais determinações estabelecidas nesta Lei e em seu regulamento.

E nem precisava deste artigo para ressaltar um pressuposto fundamental do direito: de que a lei, após a sua entrada em vigor, deve ser cumprida; e tanto mais pela Administração Pública, que tem o papel constitucional de executá-la.

O recente Decreto ํㅜ 7.404, de 23.12.2010, em seu art. 80 confirma a importância das licitações sustentáveis como medida de apoio à política nacional de resíduos sólidos. O citado artigo 80 assim dispõe:

Art.80. As iniciativas previstas no art. 42 da Lei no 12.305 , de 2010, serão fomentadas por meio das medidas indutoras:

V- fixação de critérios, metas, e outros dispositivos complementares de sustentabilidade ambiental para aquisições e contratações públicas.

As iniciativas previstas no art. 42 são justamente aquelas que irão estimular a adoção, na cadeia produtiva e de consumo nacional, da coleta seletiva, reciclagem, logística reversa, gestão ambiental, além de outras medidas que darão suporte à sistemática inaugurada pela nova lei. Trata-se, então, mais uma vez do reconhecimento da capacidade de a Administração Pública estimular essas práticas usando o seu poder de compra, pela aquisição de produtos que as respeitem, ou seja, através das licitações sustentáveis.

Em conclusão, vale ressaltar que cabe à Administração Pública, para seus novos contratos, a partir da entrada em vigor desta lei, dar exemplo, de modo organizado e bem gerenciado, no sentido do cumprimento desta lei, até com mais vigor do que outros entes privados, por missão constitucional e legal, visto que as licitações sustentáveis terão um papel de fomentadora da eficácia da nova Lei de Resíduos Sólidos. 
Entraremos, então, em um ciclo virtuoso, pois a Lei de Resíduos Sólidos nasce fortalecendo as licitações sustentáveis e estas por sua vez, cumprirão um papel importante na promoção de uma maior eficácia para a mesma lei.

\subsection{LEI DE MUDANÇAS CLIMÁTICAS}

Lei oㅜ 12.187, de 29.12.2009, que instituiu a Política Nacional sobre Mudança do Clima, a qual, em seu art. 6º, XII, elencou, como um dos instrumentos daquela Política, o estabelecimento de critérios de preferência nas licitações e concorrências públicas, inclusive nas parcerias público-privadas para proposta que propiciem maior economia de energia, água e outros recursos naturais e redução de gases de efeito estufa e de resíduos.

Podemos observar que o referido diploma legal previra apenas licitações sustentáveis de resultado, que gerem maior economia de energia, água e outros recursos naturais ou reduza a emissão de gases de efeito estufa e de resíduos, não estipulando, de forma clara e direta, sobre a escolha dos materiais, exigência de certidões ou cadastramento ou técnicas de produção ou prestação.

A discussão em torno da preservação do meio ambiente e de sua conciliação com o desenvolvimento econômico ganhou maior relevo no contexto das chamadas mudanças climáticas associadas ao aquecimento global.

A mudança do clima é comumente chamada de aquecimento global porque uma das consequências mais prováveis da existência de concentração maiores de gases de efeito estufa na atmosfera são temperaturas médias mais altas.

Segundo previsões da maior parte dos cientistas, o mundo todo sofrerá com o impacto da mudança climática já no decorrer deste século (SANTILLI, 2007, p. 358).

As descobertas científicas sobre os efeitos desta degradação para a vida humana e o seu alcance global alteraram drasticamente os termos da discussão sobre o meio ambiente. Esta mudança de percepção é narrada de forma exemplar por Friedman (2010, p. 18), "a revolução verde já não diz respeito somente a baleias. Nem aos filhos 
de nossos filhos, uma geração tão distante que torna difícil uma mobilização em seu favor. A revolução diz respeito a nós".

\section{CICLO DE VIDA DOS PRODUTOS ( Art. $7^{\circ}, \mathrm{XI}$, “a”, Lei $\mathrm{n}^{\circ}$}

\subsection{5/2010)}

A avaliação do ciclo de vida dos produtos é uma característica que perpassa toda a política pública de licitações sustentáveis.

A maioria dos instrumentos existentes para fazer opção de produtos mais sustentáveis sob o ponto de vista ambiental está baseada no conceito de ciclo de vida, um conceito holístico para avaliar a ação ambiental de um produto. A ação do ciclo de vida leva em conta o impacto ambiental do produto em todos os seus estágios, desde o nascimento, o berço (extração do material/matéria-prima), até o túmulo (disposição final), com o propósito de minimizar ao máximo o dano ambiental (BIDERMAN, 2008, p.60) .

O ciclo de vida está consagrado na Política Nacional de Resíduos Sólidos e consiste na "série de etapas que envolvem o desenvolvimento do produto, a obtenção de matérias-primas e insumos, o processo produtivo, o consumo e a disposição final" (art. 3o, VI, Lei № 12.305/2010) é de fundamental importância para a compreensão e aplicação das compras sustentáveis, uma vez que somente a sua compreensão permitirá sair da armadilha do menor preço imediato e incorporar os preços totais do produto, considerando-se o seu custo durante toda sua utilização. Mais, devem ser consideradas ainda as externalidades geradas antes e depois deste marco.

Uma atenção a esse princípio é quando a lei fala na "prioridade, nas aquisições e contratações governamentais, para produtos reciclados e recicláveis" (art. $7^{\circ}, \mathrm{XI}$, "a", Lei oํ 12.305/2010), mostrando que se deve considerar não só o produto em si, mas a forma como é feita e a forma como pode ser descartado. 
Somente com o conhecimento do ciclo de vida completo do produto é possível determinar o seu impacto ambiental e avaliá-lo para fins de critérios de sustentabilidade atinentes a licitações públicas.

\subsection{O BEM COMUM E A FUNÇÃO SOCIAL DA LICITAÇÃO SUSTENTÁVEL: A REGULAÇÃO SOCIAL}

Conforme Azambuja (2000, p. 229) "Chegou um momento em que os homens sentiram o desejo, vago e indeterminado, de que um bem que ultrapassa o seu bem particular e imediato e que ao mesmo tempo fosse capaz de garanti-lo e promovê-lo. Esse bem é o bem comum ou bem público e consiste num regime de ordem, de coordenação de esforços e intercooperação organizada".

O bem comum é um reflexo da filosofia do homem, variando de acordo com o contexto no qual se encontre. Em cada Estado há uma concepção do mundo que predomina, durante algum tempo, sobre as demais concepções.

É esta concepção do mundo que determina o conteúdo do bem comum específico do respectivo Estado. Com o passar do tempo, aquela filosofia do mundo modifica-se ou é substituída por outra, que, nesse interregno, fortaleceu-se, tonando-se predominante. Dessa forma, o direito positivo sobre alterações, no sentido de se adequar ao novo conteúdo do bem comum. Isso acontece porque o direito pretende refletir os valores (princípios) de uma dada sociedade, através das normas.

O bem comum é aquele substanciado na Constituição da República Federativa do Brasil. É lá, de suas normas e princípios que extraímos todas as informações que nos levem a identificar os fins do Estado, visando ao atendimento do bem comum temporal, no dizer de (DABIN, 1996, P.150).

Por sua vez, o bem comum temporal (autêntico) consiste nas condições materiais e morais de um meio social onde o homem possa atingir a plenitude de seu destino.

Temos nos dias de hoje, uma sociedade brasileira mais evoluída no sentido de considerar como bem comum temporal, um meio ambiente equilibrado, impondo aos 
cidadãos e ao Estado o dever de preservá-lo e defendê-lo, para as presentes e futuras gerações.

Nesse sentido, é de ressaltar que as licitações (sustentáveis) não só podem como devem ser utilizadas com fins regulatórios (não apenas econômicos), visando a implementação dos ideais previstos na Constituição Republicana.

Portanto, é um poder/dever do administrador público, visando ao atingimento do bem comum temporal, estabelecer aparentes desigualdades, para fins regulatórios.

Sobre o tema regulação social, oportunas as ponderações de Justen Filho (2011, p, 143):

Essas concepções foram objeto de intensa revisão, a propósito do que se poderia identificar como uma segunda onda intervencionista. Tratase da regulação social, que assume outras propostas. Constatou-se que o mercado, ainda que em funcionamento perfeito, pode conduzir à não realização de certos fins de interesse comum.

A realização de inúmeros outros fins, de natureza sociopolítica, também é buscada pela regulação, que não pode restringir-se a preocupações meramente econômicas.

É necessário proteger o meio ambiente, por exemplo. A racionalidade econômica imediatista conduz à destruição deste.

A regulação também orienta a garantir direitos de minorias e a promover outros valores políticos, sociais e culturais.

Em síntese, a utilização do poder de compra do Estado através das licitações sustentáveis com finalidade de regulação social, desde que respeitadas as normas e princípios constitucionais, está longe de ferir o princípio da igualdade, nem tampouco prejudica a competitividade. 
Se escolhas de produtos, por razões de conveniência e oportunidade são aceitas, com muito mais razão há que se aceitar as escolhas motivadas na necessidade de conservação e de preservação do meio ambiente (regulação social), que constitui um dever do Estado, não apenas uma mera faculdade.

A Lei oㅜ 12.349, de 15.12.2010, veio justamente ao encontro desse objetivo. A novel

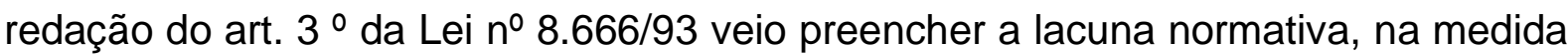
em que impõe a observância do princípio da isonomia conjugado com a promoção do desenvolvimento nacional sustentável.

\subsection{A INTERPRETAÇÃO JURÍDICA DA RECENTE ALTERAÇÃO DA LEI № 8.666/93}

O art. $3^{\circ}$ da Lei $n^{\circ}$ 8.666/93, que trata dos princípios regentes do processo licitatório, foi alterado para abrigar o conceito de desenvolvimento sustentável. Assim restou a sua nova redação:

Art. 3ำ A licitação destina-se a garantir a observância do principio constitucional da isonomia, a seleção da proposta mais vantajosa para a administração e a promoção do desenvolvimento nacional sustentável e será processada e julgada em estrita conformidade com os princípios básicos da legalidade, da impessoalidade, da moralidade, da igualdade, da publicidade, da probidade administrativa, da vinculação ao instrumento convocatório, do julgamento objetivo e dos que lhes são correlatos.

Como é notório, o conceito de desenvolvimento sustentável é um conceito, até certo ponto, em aberto e vago, já que dentre os ecólogos e ambientalistas não se chegou a um consenso absoluto acerca de todos os termos que preencheriam este conceito, pois se trata de um termo permeado por várias questões não apenas científicas, mas também ideológicas e políticas. 
Entretanto, existem elementos básicos essenciais no conceito de desenvolvimento sustentável em face dos quais existe, sim, um consenso. Trago, então, a lume, a definição dada por um consagrado clássico da literatura ecológica Corson (1996, p.54):

Desenvolvimento sustentável é aquele que satisfaz hoje as necessidades dos indivíduos, sem destruir os recursos que serão necessários no futuro. É baseado no reconhecimento de que, para manter o acesso aos recursos que tornam a vida diária possível, devemos admitir os limites de tais recursos.

Por se tratar de um conceito em aberto, não totalmente preenchido em seus elementos integrantes, é necessária extrema cautela para que não caiamos na armadilha da subjetividade. Sabemos que a subjetividade gera incertezas, insegurança jurídica, altamente prejudicial aos processos licitatórios em razão da abertura dada a impugnações e paralisações, que tanto afligem o bom andamento do serviço público. Sabemos também que tais paralisações têm, ao fim e ao cabo, como principal prejudicado a população usuária do serviço público, assim como o meio ambiente, pois em geral paralisação se traduz em desperdício, não apenas de recursos públicos, mas também de recursos materiais, de produtos da natureza, e isto significa, em última instância, dano ambiental.

Diante da incerteza, da insegurança jurídica que poderia ser gerada pelo conceito de certo modo vago de desenvolvimento sustentável , é onde se deve estabelecer certos parâmetros, e é justamente nesse ponto que as leis, de Mudança Climática e de Resíduos Sólidos, vêm em auxílio das licitações sustentáveis.

Portanto, as duas leis dão o Norte, os parâmetros, para que se definam os produtos melhores para o meio ambiente, os produtos que favorecem o desenvolvimento sustentável. Percebe-se, então, a importância dessas Leis, de Mudança do Clima e de Resíduos Sólidos, que nos dão os elementos que precisamos para melhor interpretar a nova redação do art. 3ํ da Lei oㅡ 8.666/93: produtos que propiciem maior 
economia de energia, água e outros recursos naturais e redução da emissão de gases de feito estufa e de resíduos, bem como produtos reciclados e recicláveis.

Desse modo, uma vez demonstrado nos autos do processo licitatório, que o produto escolhido pelo gestor se enquadra em algum desses elementos, estará legalmente justificada a sua escolha, sendo inclusive ilícito que o faça de modo contrário.

Vale ressaltar que nesta aplicação das leis de Resíduos Sólidos e de Mudança Climática e especialmente da nova redação do caput do art. 3ํ da Lei ํㅡ 8.666/93, há que se cuidar para que não se venha a ferir de morte os outros princípios insculpidos na Lei $n^{0}$ 8.666/93, especialmente os da isonomia/competitividade e da economicidade.

Para tanto, é crucial que tal aplicação e interpretação das leis em comento sejam efetuadas pelo gestor público e operadores jurídicos a luz dos princípios da razoabilidade e da proporcionalidade.

O princípio da proporcionalidade significa que o intérprete, em caso de dúvida, ao se deparar com a situação de ter que fazer uma escolha entre interpretações e normas diversas, deve pautar esta escolha, analisando os interesses em jogo, optando pelo mais valioso, aquele que estiver em consonância com os princípios e fins do ramo do direito e, principalmente, da Carta Magna, como neste caso, a preservação do meio ambiente, mas com o mínimo de ofensa ao outro, que a ele se contrapõe, sem que haja a violação do mínimo em que este outro deve ser respeitado, buscando, então, certo equilíbrio entre os dois.

\subsection{PRINCÍPIO DA ISONOMIA}

A lei regente das licitações é explicita no sentido de permitir a possibilidade de uma correta especificação e exigências no sentido de bem contratar, atendendo a critérios sustentáveis.

Utiliza-se outrora, de maneira errônea, o princípio da isonomia, constante do art. 3ํㅡ, inciso 1ํㅡ, da Lei ํo 8.666/93, como forma de impugnar a adoção, pelo Estado, de 
exigências que viabilizassem as licitações sustentáveis. A novel redação do art. 3ำ veio a espancar quaisquer dúvidas a esse respeito.

Outrora, alegava-se que ao direcionar a aquisição de bens e serviços de modo a propiciar o desenvolvimento sustentável, o princípio da igualdade seria um suposto impeditivo, vez que todos os licitantes deveriam, em tese, concorrer em igualdade de condições.

Sendo assim, sendo isonômica, a lei não pode discriminar arbitrariamente, qual discriminação há que observar o requisito constitucional de correlação lógica concreta entre o fator discrímen e a diferenciação dela decorrente.

Olvidavam-se os puristas que o princípio da igualdade permite o estabelecimento de distinções, desde que amparadas em justificativas respaldadas pelo ordenamento constitucional. Nesse sentido, ensina Mello ( 2010, p.20):

Em sendo abstrata, a lei é genérica, ou seja, abarca os gêneros em todas as medidas descritas. Sendo genérica, não pode excepcionar, a não ser quando as exceções forem oriundas de critérios objetivos, baseados em permissivos constitucionais inequívocos.

Como então compatibilizar o princípio da igualdade com as licitações sustentáveis?

Mesmo antes da alteração legislativa, poder-se ia justificar a compatibilização com base simplesmente no próprio art. $7^{\circ}$ da Lei $n^{\circ}$ 8.666/93, harmonizando-se a expressão tecnicamente justificável com a aspiração constitucional (art. 225) de "meio ambiente ecologicamente equilibrado, bem de uso comum do povo e essencial à sadia qualidade de vida, impondo-se ao Poder Público e à coletividade o dever de defendêlo e preserva-lo para as presentes e futuras gerações".

É fato que há situações em que a lei não só pode, mas deve discriminar, sob pena de ela (a lei), ao se abster de desigualar, estar ferindo o próprio princípio da igualdade, que exige prestações positivas por parte do Estado. 
Em síntese: o que a lei proíbe são exigências que não se sustentem juridicamente, que não guardem consonância com objeto e objetivos da licitação. O Administrador Público, ao optar pelo objeto que venha a contribuir para um meio ambiente saudável, não estará ferindo o princípio da isonomia no momento da descrição do objeto, como, por exemplo, ao exigir que os móveis sejam de madeira certificada de baixo consumo de energia, etc.

Portanto, não há que se falar em violação do princípio da igualdade se as exigências constantes no edital estiverem afinadas com o objeto e objetivos da licitação, desde que respaldados pelos princípios prestigiados pelo legislador constitucional.

Os artigos 170 e 225 da CF/88, mesmo antes da mudança legislativa, já fundamentavam e respaldavam totalmente eventuais "fatores discrimen" que viessem a ser erigidos para propiciar e respaldar a utilização, pela administração, de licitações sustentáveis na aquisição de bens e serviços.

\subsection{O PRINCÍPIO DA ECONOMICIDADE}

O princípio da economicidade determina que os recursos financeiros sejam geridos de modo adequado, para que se obtenham os maiores benefícios pelos menores custos.

Outrora, autores mais conservadores poderiam argumentar que a incorporação da variável ambiental às licitações não atenderia ao princípio da economicidade. Todavia, tal argumento não mais se sustenta, vez que adoção da variável ambiental às licitações atende a economicidade. Eventual aumento imediato de custo de produtos e serviços pode ser compensado, a médio e longo prazo, pela redução dos danos ambientais.

Tal mudança de postura, pela administração, possibilita uma visão mais sustentável e menos financeira da licitação. Portanto, o poder de compra da administração, que é a prerrogativa de definir suas exigências e necessidades, deve, sem sombra de dúvidas, 
ser utilizado com finalidades regulatórias, tornando o Estado um fomentador do desenvolvimento socioambiental.

Como resultado dessa nova postura, podemos mencionar a recente edição da Lei no 12.305, de 2.8.2010, que instituiu a Política Nacional de Resíduos Sólidos. Ela pode ser considerada um exemplo do estabelecimento de uma política pública que procura conciliar as atividades econômicas com a preservação ambiental, criando instrumentos novos como a "logística reversa" (art.3, XII) e estabelecendo uma "responsabilidade compartilhada pelo ciclo de vida do produto" (art. 3, XVII).

A Lei $\mathrm{n}^{-}$12.349, de 15.12.2010 tratou de explicitar diretamente a necessidade da adoção da variável ambiental, ao estabelecer nova redação ao art. 3ํ da Lei nº 8.666.

Seguindo essa diretriz, não foi outro entendimento do admirável Supremo Tribunal Federal, na Ação Direta de Inconstitucionalidade ADI-MC 3540 DF, que aborda a questão ambiental. Concluiu o STF, no sentido de que " atividade econômica não pode ser exercida em desarmonia com os princípios destinados a tornar efetiva a proteção ao meio ambiente, não podendo a incolumidade do meio ambiente ser comprometida por interesses empresariais nem ficar dependente de motivações de índole meramente econômica".

A licitação, portanto, pode e deve ser utilizada como instrumento de regulação econômica, de forma a induzir práticas ou produzam efeitos sociais que venham ao encontro dos desígnios constitucionais, principalmente os insculpidos no art. $1^{\circ}$ e $3^{\circ}$ da Constituição Federal.

\subsection{MEIO AMBIENTE E DESENVOLVIMENTO: O PERMEIO DA ÉTICA}

A inter-relação entre meio ambiente e desenvolvimento implica em ruptura à visão mecanicista do ser humano e do mundo, concepção que teve seus primórdios na revolução industrial e se caracterizava pela extremada confiança nas inovações tecnológicas e, paradoxalmente, em uma crença na infinitude dos recursos naturais. Consoante Dupas (2006, p. 43), “ a Revolução Industrial parecia tornar possível o 
paraíso, e sua imagem era confundida com a das capitais europeias se transformando em brilhantes espetáculos".

Com o passar do tempo, a lógica que movimentava esse paraíso, técnica, ciência e sociedade de consumo, não conduziu ao progresso almejado pelos países (ou se conduziu, produziu também consequências não desejadas, como escassez de recursos naturais ou desequilíbrios ecológicos) e questionamentos éticos passaram a permear a temática econômica-ambiental e, inclusive, a própria nação de desenvolvimento.

O desenvolvimento técnico e intelectual, apesar de sua amplitude no século passado, não teve o condão de evitar ou suplantar desequilíbrios ecológicos, evidenciado que nem todas as ações da natureza são passiveis de controle humano.

Há de se refletir sobre as noções de progresso, crescimento e desenvolvimento. Neste sentido, destacamos o atrelamento do desenvolvimento a índice econômico (PIB) que não guarda, necessariamente, correlação com o acesso à saúde, moradia e educação e a diminuição da pobreza. Mesmo o Índice de Desenvolvimento Humano (IDH) das Nações Unidas foi objeto de questionamento em atual publicação do professor Veiga (2009, p. 85):

[IDH] (...) importante avanço, embora mais no plano conceitual do que no prático, pois o IDH é um índice que resulta da média aritmética de três indicadores, um dos quais é o próprio PIB per capita. Isso faz com que precariedades nas duas outras dimensões, saúde e educação, sejam "compensadas" por alto PIB per capita .

O autor destaca que até as economias mais ecoeficientes continuam a aumentar a pressão sobre recursos naturais (p.37) e apresenta como diretriz futura a estabilização do consumo (p.55).

Podemos destacar dois aspectos: os elementos da natureza não são todos passíveis de controle e intervenção humana e as concepções de desenvolvimento passam por questionamentos e revisões. Tenha-se como exemplo os recursos não renováveis e 
os renováveis que, utilizados com maior rapidez de que sua capacidade de recomposição, findam por colocar o homem diante de dilemas econômicos e ambientais.

O enfrentamento desta nova realidade não pode desvincular-se de questionamentos éticos acerca da economia e dos valores predominantes na sociedade. Não se trata de contestação acerta do modelo capitalista, mas sim de refletir sobre as políticas que incentivam o consumo e sobre novas relações econômicos-sociais e ambientais que podem surgir localmente entre indústria e comunidade. Tenha-se por presente o emblemático caso em Bangladesh do Grameen Danone, no qual o Nobel da Paz Mohammad Yunus, por meio do banco Grameen, associou-se à Danone no desenvolvimento de um iogurte que contivesse nutrientes específicos para reduzir a desnutrição infantil em Bangladesh, produzido com energia solar e biogás.

Falar-se em sustentabilidade é falar em opções éticas que considerem a coletividade, o meio, o outro e o que advirá, em decisões difíceis e complexas que envolvem diferenças entre países desenvolvidos e em desenvolvimento e multiplicidades culturais.

Um dos grandes desafios é como o Direito se insere nesta realidade, global e local, com pressões sociais, políticas econômicas, às quais se conjugam alterações climáticas e limitações de recursos naturais, realidade de modificações mais frequentes do que os processos de positivação.

No questionamento acerca das novas relações que envolvem o consumo, destaca-se a relevância da inserção e fortalecimento da sustentabilidade nas ações governamentais, notadamente nas contratações públicas. O Estado como consumidor tem o potencial de fomentar o mercado e como empregador o de imprimir uma cultura administrativa sustentável.

Com ênfase na necessidade de posicionamentos éticos sobre a problemática ambiental, destacamos que, uma vez estabelecidas linhas e programas de ação pelo Legislativo e Executivo, a efetivação do desenvolvimento sustentável nas 
contratações públicas envolve aspectos eminentemente práticos e cotidianos, relacionados a conflitos valorativos nas opções administrativas possíveis para a execução das políticas públicas.

Neste sentido, o Direito e o jurista que interpreta e aplica tem papel fundamental. Referimo-nos, por exemplo, à normatização da prioridade nas aquisições públicas para produtos reciclados ou recicláveis (positivação) até à opção pela aquisição de um bem durável em detrimento de um descartável (decisão administrativa com lastro em valoração ambiental). Em seu proceder cotidiano o gestor público envolvido em contratações deve estar resguardado pelo órgão jurídico consultivo (art. 38, parágrafo único, Lei no 8.666/93) também nos aspectos legais-ambientais relacionados à aquisição de bens ou contratações de serviços e obras, razão pela qual temos sustentado como necessário o fortalecimento do assessoramento jurídico ambiental nas unidades consultivas da Administração Direta e indireta, na União, Estados e Municípios.

Para a promoção do desenvolvimento nacional sustentável nas contratações públicas, tanto os atos de gestão administrativa como a atividade jurídica de consultoria deverão ter como norte as diretrizes constitucionais, legislação ambiental e compromissos internacionais assumidos internacionalmente pelo Estado brasileiro.

\subsection{DIREITO INTERNACIONAL AMBIENTAL, SEUS PRINCÍPIOS E DIRETRIZES}

A constituição Federal, em seu art.84, VIII, estabelece como competência do Presidente da República a celebração de tratados, convenções e atos internacionais, sujeitos a referendo do Congresso Nacional. Aprovado por decreto legislativo, somente com a promulgação por decreto do Presidente o compromisso internacional é incorporado e se torna obrigatório, sob status de lei ordinária.

Exceção aplica-se aos tratados e convenções internacionais sobre direitos humanos que, aprovados, em cada Casa do Congresso Nacional, em dois turnos, por três 
quintos dos votos dos respectivos membros, serão equivalentes às emendas constitucionais (art. 5ำ, inciso $3^{\circ}, \mathrm{CF}$ ).

Apesar de entendimentos contrários a esta sistemática, respeitáveis por contribuírem doutrinariamente ao avanço do Direito, a posição prevalecente no Supremo Tribunal Federal é a acima exposta.

Considerado o entendimento do Supremo Tribunal Federal, ainda que o direito internacional dependa, nos dizeres de Miranda (2009, p. 30), "em larga medida, de órgãos do Direito interno para a execução das suas normas", não devemos perder de vista seu papel principiológico e orientador do direito interno.

Assim, mesmo que haja instrumentos de Direito Internacional não submetidos à sistemática de interiorização a ordenamentos nacionais, eles são o registro escrito de valores alçados consensualmente como relevantes pela comunidade internacional, valores estes que acabam por reverberar internamente nos países, mormente se versarem sobre direitos humanos, " substrato básico imprescindível do Estado de Direito".

Neste contexto, com relação aos compromissos internacionais assumidos pelo Estado brasileiro sobre sustentabilidade e, especificamente, sobre licitações sustentáveis, a práxis jurídica brasileira evidencia que eles reverberaram no ordenamento jurídico interno, ainda que não submetidos à aprovação pelo Congresso Nacional e posteriormente promulgados pelo Presidente da República.

Este pensar tem consonância com os estudos desenvolvidos por Oliveira (2000, p. 65) sobre a função exercida pela soft law na efetivação do direito ambiental internacional:

O Direito Ambiental possui muitos princípios proclamados em várias declarações internacionais que acabam por orientar a criação de normas e aplicação de instrumentos para a proteção do meio ambiente. Na recente história do Direito Ambiental Internacional, dois eventos globais foram marcantes por oferecerem uma reflexão acerca da proteção ao meio ambiente. São eles: Conferência das Nações 
Unidas sobre o Meio Ambiente Humano, realizada na Suécia (Estocolmo), em 1972, e a Conferência das Nações Unidas sobre o Meio Ambiente e Desenvolvimento, realizada no Brasil (Rio de Janeiro) em 1992.

De efeito, o conteúdo principiológico de compromissos internacionais transpassa a sistemática jurídica de incorporação de tratados ao ordenamento nacional e norteia o Estado brasileiro na implementação de políticas públicas voltadas ao desenvolvimento sustentável e às licitações sustentáveis.

\section{CONCLUSÃO}

Diante do exposto, observa-se que a licitação sustentável, em síntese, consiste em uma tentativa de a Administração Pública colaborar com desenvolvimento no qual há progresso material, tecnológico, mas sem comprometer a existência saudável de gerações futuras, sem esgotamento dos recursos naturais não renováveis, preservando as condições habitáveis de vida que ainda restam no planeta.

Com a admissão paulatina de medidas, onde só poderá participar do certame o competidor cujo produto ou serviço cumpra parâmetros ambientais adequados, além de deter a aptidão necessária para executar o objeto contratual dentro desses mesmos parâmetros. Por outro lado, caso deixe de atender aos critérios esperados, será sancionado de acordo com a gravidade da conduta praticada, vendo-se obrigado a conformar suas práticas comerciais às normas ambientais vigentes para evitar novas punições.

A implementação concreta das licitações sustentáveis dará à Administração o poder de, a longo prazo, moldar o mercado de fornecedores, no sentido de assegurar a permanência daquelas empresas que efetivamente contribuem com as diretrizes de proteção ao meio ambiente, bem como fomentar a mudança de direção das demais empresas forçadas a se adaptarem as mesmas condições.

É claro que tal processo leva tempo, e nem poderia ser diferente. A Administração deve pautar sua atuação de forma coerente com a configuração atual do mercado. As 
alterações devem ser introduzidas gradualmente, para incentivar a adaptação de fornecedores no sentido de considerar os aspectos socioambientais na atividade econômica que exercem. Só assim a Administração exercerá seu papel de fomentar as boas práticas de sustentabilidade. Nesse sentido, cabe destacar a importância de atuação da AGU e TCU na implementação e fiscalização nas contratações, respectivamente. A fim de assegurar o cumprimento legal das licitações públicas sustentáveis.

A tendência é de gradualmente conceder-se preferência aos produtos e serviços socioambientalmente adequados, até que dominem o mercado.

No entanto, quaisquer medidas legais serão inócuas, a não ser que o gestor público assuma seu relevante dever para com a sociedade e as implemente efetivamente.

Portanto, o poder de imprimir tais alterações, fundamentais no modo de agir do setor produtivo, está mais do que nunca, nas mãos do gestor público.

\section{REFERÊNCIAS}

ARAGÃO, Alexandre Santos de. Curso de Direito Administrativo. Forense. Rio de Janeiro: 2012.

ARAÚJO, Edmir Netto de. Curso de Direito Administrativo. Saraiva. Rio de Janeiro: 2010.

AZAMBUJA, Darcy. Teoria Geral do Estado. Globo. Rio de Janeiro: 2000.

BIDERMAN, Rachel. et al. (Org). Guia de compras públicas sustentáveis: uso do poder de compra do governo para a promoção do desenvolvimento sustentável. ICLEI Governos Locais pela Sustentabilidade, Secretariado para América Latina e Caribe LACS: 2008.

CANEPA, Carla. Cidades sustentáveis: o município como lócus da sustentabilidade. Saraiva, Rio de Janeiro: 2007. 
CORSON, Walter H. (Ed.). Manual global de ecologia: o que você pode fazer a respeito da crise do meio ambiente. Augustus,1996.

DABIN, Jean. Teoria geral do direito tributário. 5ª ed., Forense. São Paulo: 1996 .

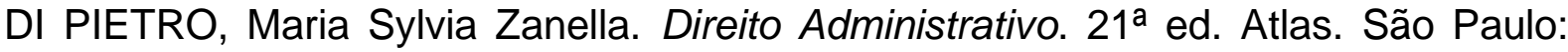
2008.

DUPAS, Gilberto. O mito do progresso, ou, Progresso como ideologia. Unesp, São Paulo, 2006.

FERREIRA, Maria Augusta Soares de Oliveira. As licitações públicas e as novas leis de mudança climática e de resíduos sólidos. In: SANTOS, Murillo Giordan; BARKI, Teresa Villac Pinheiro (Coord.). Licitações e contratações públicas sustentáveis. Fórum, Belo Horizonte: 2011.

FRIDEMAN, Thomas L. Quente, plano e lotado: os desafios e oportunidades de um novo mundo. Objetiva. 2010.

JUSTEN FILHO, Marçal. Curso de Direito Administrativo. Fórum. Belo Horizonte: 2011.

MELLO, Celso Antonio Bandeira de. O conteúdo jurídico do princípio da igualdade. Malheiros. São Paulo: 2011.

MELLO, Celso Antônio Bandeira de. O conteúdo jurídico do principio da igualdade. $3^{a}$ ed. Malheiros, São Paulo, 2010.

MEIRELLES, Helly Lopes. Direito administrativo brasileiro. $37^{a}$ ed. Malheiros. São Paulo: 2011.

MIRANDA, Jorge. Curso de direito internacional público. $4^{\underline{a}}$ ed. Forense, Rio de Janeiro, 2009. 
OLIVEIRA, Rafael Santos. Direito ambiental internacional: o papel da soft law em sua efetivação. Unijui, Rio Grande do Sul: 2000.

PEREIRA JUNIOR, Jessé Torres. Desenvolvimento sustentável: a nova cláusula geral das contratações públicas brasileiras. Revista Interesse Público IP, Belo Horizonte: 2011.

SACHS, Ignacy. Caminhos para o desenvolvimento sustentável. Garamond. Rio de Janeiro: 2000.

SANTILLI, Marcio. Mudança climática global. In: Almanaque Brasil socioambiental: uma nova perspectiva para entender a situação do Brasil e a nossa contribuição para a crise planetária. Instituto socioambiental. São Paulo: 2007.

SANTOS, Murillo Giordan; BARKI, Teresa Villac Pinheiro (Coord.). Licitações e contratações públicas sustentáveis. Fórum. Belo Horizonte: 2011.

STROPPA, Christiane de Carvalho. Licitação Sustentável. Seminário Internacional de Compras Governamentais.

TRIGUEIRO, André. Meio ambiente no século 21, Autores Associados LTDA. Campinas: 2005.

VEIGA, José Eli. Mundo em transe: do aquecimento global ao ecodesenvolvimento. Autores Associados, São Paulo, 2009.

CADTERC - Cadastro de Serviços Terceirizados. Disponível em http://www.cadterc.sp.gov.br. Acesso em 02/02/2019.

Enviado: Fevereiro, 2019.

Aprovado: Março, 2019. 